\title{
Insulin resistance derived from zinc deficiency in non-diabetic patients with chronic hepatitis $\mathbf{C}$
}

\author{
TAKASHI HIMOTO ${ }^{1,2}$, HIROHITO YONEYAMA ${ }^{1}$, AKIHIRO DEGUCH ${ }^{1}$, KAZUTAKA KUROKOHCHI ${ }^{1}$, \\ MICHIO INUKAI ${ }^{2}$, HISASHI MASUGATA ${ }^{2}$, FUMINORI GODA ${ }^{2}$, SHOICHI SENDA ${ }^{2}$, \\ SEISHIRO WATANABE ${ }^{3}$, SATORU KUBOTA $^{4}$, SHIGEKI KURIYAMA $^{1}$ and TSUTOMU MASAKI $^{1}$
}

Departments of ${ }^{1}$ Gastroenterology and Neurology, and ${ }^{2}$ Integrated Medicine, Kagawa University School of Medicine;

${ }^{3}$ Department of Internal Medicine, Kagawa Prefectural Central Hospital, Kagawa; ${ }^{4}$ Medico Consl, Osaka, Japan

Received January 26, 2010; Accepted April 28, 2010

DOI: $10.3892 /$ etm_00000109

\begin{abstract}
Chronic hepatitis C virus (HCV) infection frequently evokes metabolic abnormalities including insulin resistance. A decrease in serum zinc ( $\mathrm{Zn}$ ) levels is often observed in association with hepatic fibrosis. Zn also plays important roles in insulin secretion. However, little is known about the relationship between $\mathrm{Zn}$ deficiency and insulin resistance in patients with HCV-related chronic liver disease. The main purpose of this study was to examine the contribution of $\mathrm{Zn}$ deficiency to insulin resistance in patients with chronic hepatitis $\mathrm{C}(\mathrm{CH}-\mathrm{C})$. Forty-eight non-diabetic patients with $\mathrm{CH}-\mathrm{C}$ were enrolled. Serum alanine aminotransferase (ALT), ferritin and $\mathrm{Zn}$ levels were examined in the enrolled patients with $\mathrm{CH}-\mathrm{C}$. Insulin resistance was determined by the Homeostasis model for assessment of insulin resistance (HOMA-IR). Zn deficiency was defined as serum $\mathrm{Zn}$ levels $<65 \mu \mathrm{g} / \mathrm{dl}$. Seven out of the 48 (15\%) patients with $\mathrm{CH}-\mathrm{C}$ fulfilled the criteria for $\mathrm{Zn}$ deficiency. Serum $\mathrm{Zn}$ levels were inversely correlated with serum ferritin levels $(r=-0.364, p=0.0140)$. The values of HOMA-IR were positively linked to serum ferritin levels $(r=0.299$, $\mathrm{p}=0.0484$ ). The mean value of HOMA-IR in the $\mathrm{Zn}$ deficiency group was significantly higher than that in the normal-range Zn group (3.76 \pm 0.66 vs. $2.08 \pm 1.35, \mathrm{p}=0.0019)$. Serum ALT levels were also closely associated with serum ferritin levels $(\mathrm{r}=0.727, \mathrm{p}<0.001)$. These findings were independent of $\mathrm{HCV}$ genotypes or loads of HCV-RNA. Our data suggest that iron
\end{abstract}

Correspondence to: Dr Takashi Himoto, Department of Integrated Medicine, Kagawa University School of Medicine, 1750-1, Ikenobe, Miki-Cho, Kita-Gun, Kagawa 761-0793, Japan

E-mail: thimoto@med.kagawa-u.ac.jp

Abbreviations: ALT, alanine aminotransferase; $\mathrm{CH}-\mathrm{C}$, chronic hepatitis $\mathrm{C}$; $\mathrm{HCV}$, hepatitis $\mathrm{C}$ virus; CLD, chronic liver disease; DM, diabetes mellitus; HOMA, homeostasis model assessment; IR, insulin resistance; 8-OHdG, 8-hydroxy-2'-deoxyguanosine; SOD, superoxide dismutase; $\mathrm{Zn}$, zinc

Key words: chronic hepatitis, hepatitis C virus, insulin resistance, iron overload, zinc overload in patients with $\mathrm{CH}-\mathrm{C}$ derives from $\mathrm{Zn}$ deficiency and thereby causes insulin resistance.

\section{Introduction}

Zinc $(\mathrm{Zn})$ is an essential trace element that serves as the active center of approximately 300 enzymes and participates in physiological functions including immune function, neurosensory function, protein metabolism, wound healing and sexual function $(1,2)$. Zn plays important roles as a growth co-factor, an immunomodulator and a cytoprotectant with antioxidant, antiapoptotic and anti-inflammatory effects $(3,4)$. Therefore, $\mathrm{Zn}$ depletion results in numerous types of symptoms including taste disorder, hyperkeratotic skin change, wound healing disturbance and testicular dysfunction.

$\mathrm{Zn}$ deficiency is also frequently observed in patients with chronic liver diseases (CLD), including chronic hepatitis and liver cirrhosis (5-8). Serum $\mathrm{Zn}$ levels inversely correlate with the severity of hepatic fibrosis (7). Zn depletion in patients with liver cirrhosis is closely related to the progression of hepatic encephalopathy. Zn deficiency usually leads to a decrease in the activity of ornitine transcarbamylase, a key Zn-containing enzyme for the urea cycle. This consequently causes the accumulation of ammonia and seems to account for the pathogenesis of hepatic encephalopathy (9). Zn administration has favorable effects on the inhibition of hepatic fibrosis, activating collagenase, which belongs to a zinc-metallo-enzyme, and/or diminishing prolyl hydroxylase, which contributes to collagen synthesis (10). Zn supplementation also relieves hepatic encephalopathy. In addition, we previously elucidated that oral administration of polaprezinc, a complex of zinc and l-carnosine, markedly improved necroinflammation in the liver of hepatitis $\mathrm{C}$ virus (HCV)-related CLD, reducing iron overload in the liver (11).

It has been widely established that persistent $\mathrm{HCV}$ infection leads to metabolic abnormalities including insulin resistance, hepatic steatosis and hypertriglycemia $(12,13)$. Impaired signaling of the insulin receptor substrate (IRS) by the $\mathrm{HCV}$ core protein is considered to trigger insulin resistance in patients with HCV-related CLD (14). Previous studies revealed that insulin resistance is significantly associated with body mass index (BMI) (15), hepatic steatosis (16), hepatic 
fibrosis $(17,18)$ and/or iron overload (19) in patients with chronic hepatitis $\mathrm{C}(\mathrm{CH}-\mathrm{C})$.

On the other hand, $\mathrm{Zn}$ also plays crucial roles in the secretion and activation of insulin (20). Therefore, abnormalities of $\mathrm{Zn}$ metabolism seem to be associated with the pathogenesis of type 2 diabetes mellitus (DM) (21). A recent report revealed that oral administration of a $\mathrm{Zn}$ complex improved glucose tolerance in an experimental model of type 2 DM (22).

However, little is known about the relationship between insulin resistance and $\mathrm{Zn}$ deficiency in patients with HCV-related CLD. The primary purpose of this study was to investigate whether or not $\mathrm{Zn}$ deficiency contributes to insulin resistance in patients with $\mathrm{HCV}$-related CLD.

\section{Materials and methods}

Study population. Forty-eight non-diabetic patients with $\mathrm{CH}-\mathrm{C}$, who had HCV-RNA detectable in the sera by polymerase chain reaction (PCR) and showed histological characteristics consistent with chronic hepatitis, were randomly selected for this study. Informed consent was obtained from the enrolled patients.

Laboratory assessments. The severity of obesity was evaluated using BMI. Insulin resistance was determined by the Homeostasis model for assessment of insulin resistance (HOMA-IR) method using the following equation: HOMA-IR $=$ fasting insulin $(\mu \mathrm{U} / \mathrm{ml}) \mathrm{x}$ fasting glucose $(\mathrm{mg} / \mathrm{dl}) / 405(23)$. Serum alanine aminotransferase (ALT) levels were assessed as a serological parameter of necroinflammation in the liver. Serum ferritin levels were examined as a serological hallmark of iron storage in the liver. Blood samples were drawn in the morning with fasting on the basis of circadian serum $\mathrm{Zn}$ levels (24). Zn deficiency was defined as a serum $\mathrm{Zn}$ level $<65 \mu \mathrm{g} / \mathrm{dl}$, which corresponds to the normal lower limit of normal serum $\mathrm{Zn}$. Quantitative detection of serum HCV-RNA was performed by Amplicor-HCV monitor assay (Roche Molecular Diagnostics, Tokyo, Japan) (25). The HCV genotype was determined by the HCV-RNA Genotyping assay system (Home Brew SRL Inc., Tokyo, Japan) (26).

Evaluation of hepatic fibrosis and steatosis. The grades of hepatic fibrosis were determined by the New Inuyama classification system, which is a standard criterion for the histological assessment of chronic hepatitis in Japan (27). The stages in chronic hepatitis were classified from $\mathrm{F}_{0}$ through $\mathrm{F}_{3} . \mathrm{F}_{0}$ was defined as no fibrosis in the liver, while $\mathrm{F}_{4}$ was defined as liver cirrhosis. The enrolled patients were divided into two groups on the basis of hepatic fibrosis: early-stage $\left(\mathrm{F}_{0}\right.$ and $\left.\mathrm{F}_{1}\right)$ and latestage $\left(\mathrm{F}_{2}\right.$ and $\left.\mathrm{F}_{3}\right)$.

The severity of hepatic steatosis was evaluated in accordance with the classification proposed by Brunt and colleagues (28): grade 0 , no steatosis; grade $1,<33 \%$ of hepatocytes with steatosis; grade 2, 33-66\% of hepatocytes affected.

Statistical analyses. Data values are represented as means \pm standard deviation (SD). The Mann-Whitney U test was applied for the comparison of continuous variables. The linear regression analysis was used to analyze the relation of the serum ferritin levels with serum $\mathrm{Zn}$ and ALT levels, or
Table I. Demographic, viral and histological characteristics of 48 patients with chronic hepatitis $\mathrm{C}$.

\begin{tabular}{lr}
\hline Characteristics & \multicolumn{1}{c}{ Data } \\
\hline Age (range) & $59 \pm 11(23-76)$ \\
Gender (male/female) & $34 / 14$ \\
Body mass index (range) & \\
Genotype & $32(67 \%)$ \\
$1 \mathrm{~b}$ & $11(23 \%)$ \\
$2 \mathrm{a}$ & $5(10 \%)$ \\
$2 \mathrm{~b}$ & \\
Hepatic fibrosis & $1(2 \%)$ \\
$\mathrm{F}_{0}$ & $20(42 \%)$ \\
$\mathrm{F}_{1}$ & $6(12 \%)$ \\
$\mathrm{F}_{2}$ & $21(44 \%)$ \\
$\mathrm{F}_{3}$ & \\
Hepatic steatosis & $27(57 \%)$ \\
Grade 0 & $16(33 \%)$ \\
Grade 1 & $5(10 \%)$ \\
Grade 2 & $7(15 \%)$ \\
Zinc deficiency & \\
\hline
\end{tabular}

the values of HOMA-IR. p-values $<0.05$ were considered to indicate a significant difference between groups.

\section{Results}

Demographic features of the enrolled patients with $\mathrm{CH}-\mathrm{C}$. Demographic characteristics are shown in Table I. Of the enrolled patients, $32(67 \%)$ had a HCV genotype of $1 \mathrm{~b}, 11$ (23\%) had a genotype of $2 \mathrm{a}$ and $5(10 \%), 2 \mathrm{~b}$, respectively. There were no significant differences in the serum $\mathrm{Zn}$ levels among the enrolled patients with the three HCV genotypes (genotype 1b, 79.5 \pm 15.1 ; 2a, 71.9 $\pm 9.8 ; 2 b, 70.4 \pm 7.0$ ). Serum $\mathrm{Zn}$ levels were not associated with the load of HCV-RNA $(\mathrm{r}=0.0074, \mathrm{p}=0.6230)$.

Of the 48 patients with $\mathrm{CH}-\mathrm{C}, 1$ had no fibrosis $\left(\mathrm{F}_{0}\right)$ in the liver and 20 patients had stage $F_{1}$ fibrosis. Six and 21 patients with $\mathrm{CH}-\mathrm{C}$ fulfilled stage $\mathrm{F}_{2}$ and $\mathrm{F}_{3}$ fibrosis, respectively. Therefore, the enrolled patients were divided into 2 groups: 21 patients with $\mathrm{CH}-\mathrm{C}$ in the early stage of hepatic fibrosis and 27 patients with $\mathrm{CH}-\mathrm{C}$ in the late stage of hepatic fibrosis.

Severity of hepatic steatosis in the enrolled patients was evaluated as follows: 27 (57\%) out of the 48 patients with $\mathrm{CH}-\mathrm{C}$ had no hepatic steatosis (grade 0). Sixteen (33\%) and $5(10 \%)$ patients had hepatic steatosis of grade 1 and grade 2, respectively.

Seven out of the 48 (15\%) patients with $\mathrm{CH}-\mathrm{C}$ fulfilled the criteria for $\mathrm{Zn}$ deficiency. These 7 patients with $\mathrm{CH}-\mathrm{C}$ had hepatic fibrosis of stage $\mathrm{F}_{2}$ or $\mathrm{F}_{3}$.

Correlation between serum ferritin levels and serum $\mathrm{Zn}$ levels, HOMA-IR values or serum ALT levels. The relationship between serum feritin and $\mathrm{Zn}$ levels in the enrolled patients with $\mathrm{CH}-\mathrm{C}$ was examined. As shown in Fig. 1A, the serum ferritin levels were inversely correlated with the serum $\mathrm{Zn}$ 

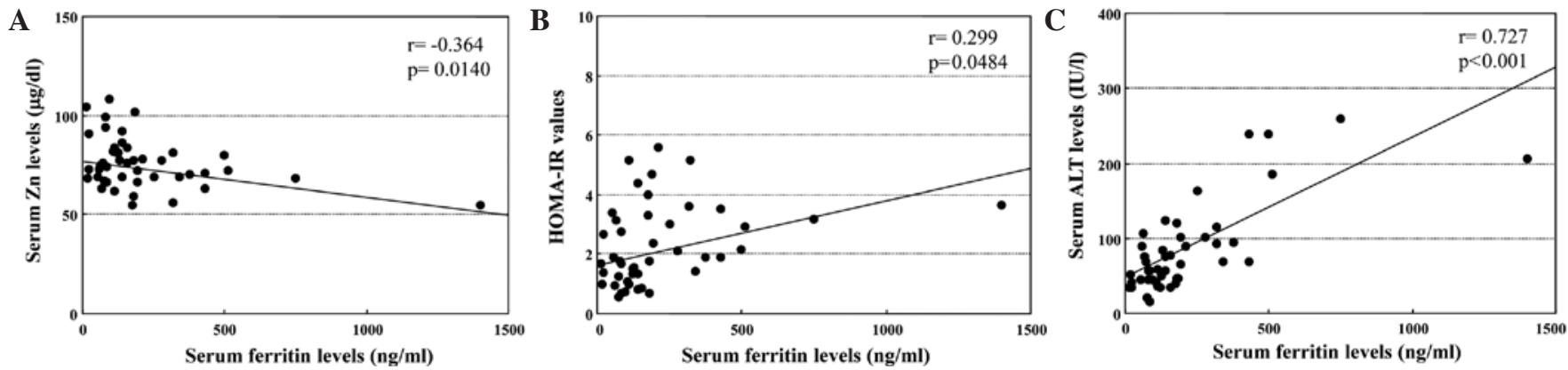

Figure 1. Correlation between serum ferritin levels and serum Zn levels (A), HOMA-IR values (B) or serum ALT levels (C) in patients with CH-C.

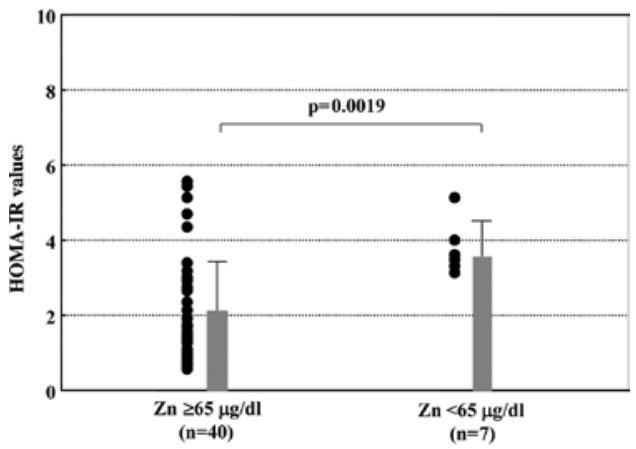

Figure 2. Comparison of HOMA-IR values between the Zn-deficient group and the group with a normal range of $\mathrm{Zn}$ values. Columns and bars represent the mean values \pm SDs of the enrolled patients.

levels $(\mathrm{r}=-0.364, \mathrm{p}=0.0140)$. The correlation was independent of HCV genotype or load of HCV-RNA (data not shown).

Moreover, serum ferritin levels were significantly associated with serum HOMA-IR values in the enrolled patients $(r=0.299, p=0.0484$, Fig. 1B), regardless of HCV genotype or load of HCV-RNA. On the other hand, the linear regression analysis showed a close relationship between serum ferritin and ALT concentrations in patients with $\mathrm{CH}-\mathrm{C}(\mathrm{r}=0.727$, p $<0.001$, Fig. 1C).

Comparison of insulin resistance between $\mathrm{Zn}$-deficient and normal $\mathrm{Zn}$ groups. The values of HOMA-IR were compared between the group with Zn-deficiency and the group whose $\mathrm{Zn}$ levels were within a normal range. As shown in Fig. 2, the mean value of HOMA-IR was significantly higher in the $\mathrm{Zn}$-deficient than that in the normal $\mathrm{Zn}$ group $(3.76 \pm 0.66$ vs. $2.08 \pm 1.35, \mathrm{p}=0.0019$ ).

Relationship between hepatic fibrosis and serum Zn levels or HOMA-IR values. The relationship between the severity of hepatic fibrosis and serum $\mathrm{Zn}$ levels or insulin resistance in the enrolled patients with $\mathrm{CH}-\mathrm{C}$ was investigated. $\mathrm{CH}-\mathrm{C}$ patients at late stages of hepatic fibrosis $\left(\mathrm{F}_{2}\right.$ and $\left.\mathrm{F}_{3}\right)$ had significantly lower serum $\mathrm{Zn}$ levels than those at early stages of hepatic fibrosis $\left(\mathrm{F}_{0}\right.$ and $\left.\mathrm{F}_{1}\right)(73 \pm 13$ vs. $81 \pm 13 \mu \mathrm{g} / \mathrm{dl}, \mathrm{p}=0.0366$, Fig. 3A). However, there were no significant differences in the HOMA-IR values between early- and late-stage hepatic fibrosis patients $(2.19 \pm 1.55$ vs. $2.44 \pm 1.30$, p=0.5527, Fig. 3B).

Other factors contributing to insulin resistance in patients with $\mathrm{CH}-\mathrm{C}$. Recent reports revealed that BMI (15) and hepatic
A

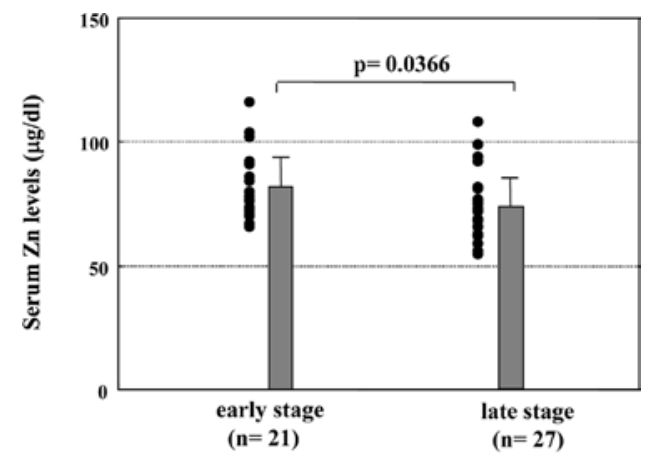

B

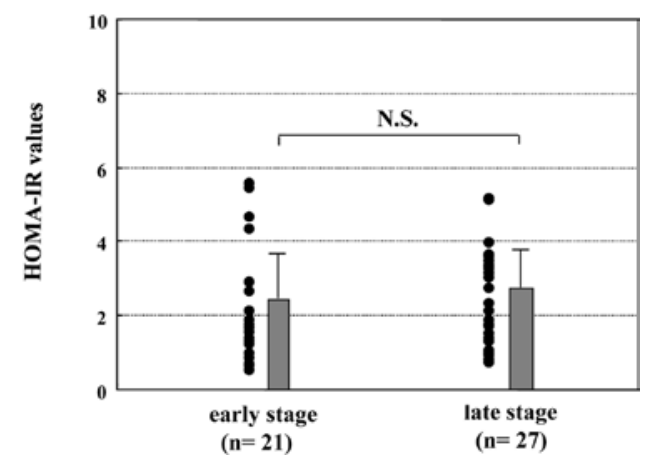

Figure 3. Comparison of serum Zn levels (A) and HOMA-IR values (B) between early- and late-stage hepatic fibrosis in patients with $\mathrm{CH}-\mathrm{C}$. Columns and bars represent the mean values \pm SDs of the enrolled patients. NS, not significant.

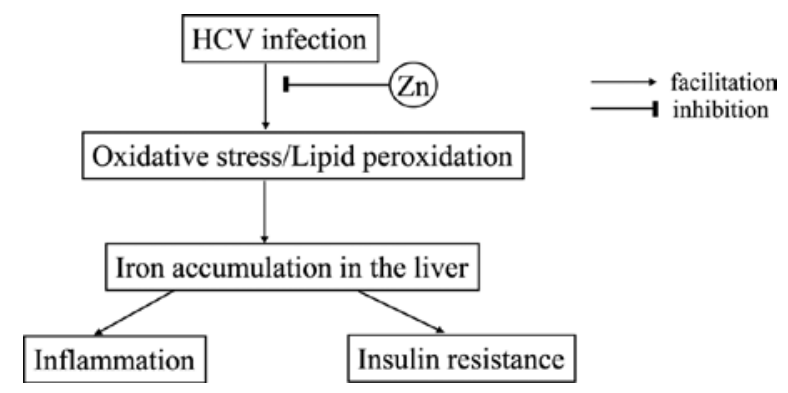

Figure 4. Postulated mechanism of insulin resistance caused by $\mathrm{Zn}$ deficiency in patients with $\mathrm{CH}-\mathrm{C}$.

steatosis (16) also affect insulin resistance in patients with $\mathrm{CH}-\mathrm{C}$. We confirmed that the mean HOMA-IR value in $\mathrm{CH}-\mathrm{C}$ patients with hepatic steatosis of grade 2 was significantly higher than that in those without hepatic steatosis $(3.88 \pm 1.08$ vs. $1.90 \pm 1.20, \mathrm{p}=0.0044)$. However, there was no significant 
correlation between the HOMA-IR value and BMI ( $\mathrm{r}=0.015$, $\mathrm{p}=0.9203)$.

\section{Discussion}

In this study, we revealed that insulin resistance in patients with $\mathrm{CH}-\mathrm{C}$ is closely associated with $\mathrm{Zn}$ deficiency (Fig. 2). $\mathrm{Zn}$ deficiency was found in $15 \%$ of the patients with chronic hepatitis. To our knowledge, this is the first report that describes the relationship between insulin resistance and $\mathrm{Zn}$ deficiency in patients with $\mathrm{CH}-\mathrm{C}$. Previously, Furutani and colleagues revealed that insulin resistance was characterized by iron accumulation in the liver (19). We confirmed the correlation between insulin resistance and iron overload in patients with $\mathrm{CH}-\mathrm{C}$ and postulated that iron overload may derive from $\mathrm{Zn}$ deficiency. The data obtained in the present study suggest the possible mechanism of insulin resistance in patients with CH-C (Fig. 4).

It is well recognized that chronic $\mathrm{HCV}$ infection eventually leads to reactive oxygen species in the liver (29). The oxidative stress induced by HCV infection consequently facilitates iron storage in the liver. On the other hand, $\mathrm{Zn}$ plays crucial roles in antioxidative actions and confers protective effects on hepatocytes $(3,4)$. $\mathrm{Zn}$ deficiency has been shown to result in attenuation of antioxidative properties and thereby a significant elevation in the serum ferritin level, which corresponds to iron accumulation in the liver. Iron overload in the liver eventually evokes insulin resistance (19), as well as necroinflammation (30) in the liver.

To date, several types of oxidative stress markers, including 8-hydroxy-2'-deoxyguanosine (8-OHdG), malondialdehyde (MDA), 4-hydroxy-2'-nonenal (4-HNE) and thioredoxin, have been identified. On the other hand, superoxide dismutase (SOD) and glutathione peroxidase are well recognized as useful hallmarks for scavengers of oxidative stress. Patients with CH-C usually show increased serum and liver levels of these oxidant products as well as attenuation of antioxidant defenses. Oxidative stress sequentially leads to lipid peroxidation, hepatic steatosis and finally hepatocarcinogenesis in patients with HCV-related CLD (31).

The hypothesis that oxidative stress by persistent $\mathrm{HCV}$ infection enhances excessive iron accumulation in the liver is supported by a recent study (32). Fujita and colleagues revealed that hepatic 8-OHdG counts in patients with $\mathrm{CH}-\mathrm{C}$ were significantly correlated with serum ferritin levels, indicating that oxidative stress caused by $\mathrm{HCV}$ infection is strongly associated with iron overload.

In the present study, we determined that hyperferritinemia, which reflects iron storage in the liver, in the patients with $\mathrm{CH}-\mathrm{C}$ may be responsible for the $\mathrm{Zn}$ deficiency (Fig. 1). The decrease in the activity of copper/zinc-SOD due to $\mathrm{Zn}$ deficiency may account for iron overload in patients with $\mathrm{CH}-\mathrm{C}$.

An inverse correlation between serum ferritin and $\mathrm{Zn}$ levels is also observed in patients with $\beta$-thalassemia (33), which fulfills the criteria for secondary iron overload syndrome. Notably, iron overload and Zn deficiency in these patients may play a part in the pathogenesis of impaired glucose tolerance (34).

Hyperferritinemia primarily seems to be responsible for the down-regulation of hepcidin, which has been recognized as a peptide hormone modulating iron uptake from the small intestine (35) and/or up-regulation of transferrin receptors (36). Miura and colleagues (35) recently revealed that a decrease in the activity of hepcidin caused by HCV-induced oxidative stress was primarily derived from i) the stabilization of the negative hepcidin regulators, hypoxia inducible factor (HIF) $1 \alpha$ and HIF2 $\alpha$, and ii) the hypoacetylation of histone and subsequent inhibition of the binding of two positive regulators, CCAT/enhancer-binding protein $\alpha(\mathrm{C} / \mathrm{EBP} \alpha)$ and the signal transducer and activator of transcription 3 (STAT3), to the hepcidin promoter.

A close relationship between insulin resistance and iron overload has been observed in patients with type 2 DM (37). We also revealed that iron overload participated in insulin resistance in patients with $\mathrm{CH}-\mathrm{C}$ (Fig. 1). Moreover, we confirmed that iron overload in patients with $\mathrm{CH}-\mathrm{C}$ eventually caused liver damage (Fig. 1).

It has been well established that the severity of hepatic fibrosis is inversely related to serum $\mathrm{Zn}$ levels (11). Previous reports affirm that the degree of hepatic fibrosis is associated with insulin resistance in patients with HCV-related CLD $(12,17,18)$. However, we did not confirm the relationship between hepatic fibrosis and insulin resistance in patients with $\mathrm{CH}-\mathrm{C}$. Other factors including iron overload may contribute to insulin resistance in patients with $\mathrm{CH}-\mathrm{C}$.

The data described above allowed us to predict that $\mathrm{Zn}$ supplementation may facilitate protection against oxidative stress caused by HCV infection, subsequently reduce hepatic iron accumulation and thereby improve insulin resistance. Further clinical trials are required to investigate this prediction.

In conclusion, $\mathrm{Zn}$ deficiency is likely to contribute to iron overload in patients with $\mathrm{CH}-\mathrm{C}$. Therefore, $\mathrm{Zn}$ deficiency seems to be an important factor contributing to insulin resistance in patients with $\mathrm{CH}-\mathrm{C}$.

\section{References}

1. McClain CJ, Kasarskis EJ and Allen JJ: Functional consequences of zinc deficiency. Prog Food Nutr Sci 9: 185-226, 1985.

2. McClain CJ, Marsano L, Burk RF and Bacon B: Trace metals in liver disease. Semin Liver Dis 11: 321-339, 1991.

3. Prasad AS: Zinc and immunity. Mol Cell Biochem 188: 63-69, 1998.

4. Powell SR: The antioxidant properties of zinc. J Nutr 130: S1447-S1454, 2000.

5. Vallee BL, Wacker WEC, Bartholomay AF, Robin ED, Vallee RL and Wacker WE: Zinc metabolism in hepatic dysfunction. I. Serum zinc concentrations in Laennëc's cirrhosis and their validation by sequential analysis. N Engl J Med 255: 403-408, 1956.

6. Bode JC, Hanisch P, Henning H, Koenig W, Richter FW and Bode C: Hepatic zinc content in patients with chronic active and chronic persistent hepatitis. Hepatology 8: 1650-1659, 1988.

7. Moriyama M, Matsumura H, Fukushima A, et al: Clinical significance of evaluation of serum zinc concentrations in C-viral chronic liver disease. Dig Dis Sci 51: 1967-1977, 2006.

8. Stamoulis I and Kouraklis G: Zinc and liver: an active interaction. Dig Dis Sci 52: 1595-1612, 2007.

9. Riggio O, Merli M, Capocaccia L, et al: Zinc supplementation reduces blood ammonia and increases liver ornithine transcarbamylase activity in experimental cirrhosis. Hepatology 16: 785-789, 1992.

10. Gimenez A, Pares A, Alie S, et al: Fibrogenic and collagenolytic activity in carbon-tetrachloride-injured rats: beneficial effects of zinc administration. J Hepatol 21: 292-298, 1994.

11. Himoto T, Hosomi N, Nakai S, et al: Efficacy of zinc administration in patients with hepatitis $\mathrm{C}$ virus-related chronic liver disease. Scand J Gastroenterol 42: 1078-1087, 2007. 
12. Fartoux L, Poujol-Robert A, Guechot J, Wendum D, Poupon R and Serfaty L: Insulin resistance is a cause of steatosis and fibrosis progression in chronic hepatitis C. Gut 254: 1003-1008, 2005.

13. Mirandola S, Realdon S, Iqbal J, et al: Liver microsomal triglyceride transfer protein is involved in hepatitis $\mathrm{C}$ liver steatosis. Gastroenterology 130: 1661-1669, 2006.

14. Aytug S, Reich D, Sapiro LE, Berstein D and Begum N: Impaired IRS-1/PI3-kinase signaling in patients with HCV: a mechanism for increased prevalence of type diabetes. Hepatology 38 : 1384-1392, 2003.

15. Maeno T, Okumura A, Ishikawa $\mathrm{T}$, et al: Mechanisms of increased insulin resistance in non-cirrhotic patients with chronic hepatitis C virus infection. J Gastroenterol Hepatol 18 : 1358-1363, 2003.

16. Camma C, Bruno S, Di Marco V, et al: Insulin resistance is associated with steatosis in nondiabetic patients with genotype 1 chronic hepatitis C. Hepatology 43: 64-71, 2006.

17. Moucari R, Asselah T, Cazals-Hatem D, et al: Insulin resistance in chronic hepatitis $\mathrm{C}$ : association with genotypes 1 and 4, serum HCV-RNA levels and liver fibrosis. Gastroenterology 134: 416-423, 2008

18. Hui JM, Sud A, Farrell GC, et al: Insulin resistance is associated with chronic hepatitis $\mathrm{C}$ and virus infection fibrosis progression. Gastroenterology 125: 1695-1704, 2003.

19. Furutani M, Nakashima T, Hirohama A, et al: Insulin resistance/ $\beta$ cell function and serum ferritin level in non-diabetic patients with hepatitis C virus infection. Liver Int 23: 294-299, 2003.

20. Chausmer AB: Zinc, insulin and diabetes. J Am Coll Nutr 17: 109-115, 1998

21. Kinlaw WB, Levine AS, Morley JE, Silvis SE and McClain CJ: Abnormal zinc metabolism in type II diabetes mellitus. Am J Med 75: 273-277, 1983

22. Adachi Y, Yoshida J, Kodera Y, et al: Oral administration of a zinc complex improves type 2 diabetes and metabolic syndrome. Biochem Biophys Res Commun 351: 165-170, 2006.

23. Mattews DR, Hosker JP, Rudenski AS, Naylor BA, Trecher DF and Turner RC: Homeostasis model assessment: insulin resistance and beta-cell function from fasting plasma glucose and insulin concentration in man. Diabetologia 28: 412-429, 1985.

24. Lifschitz MD and Henkin RI: Circadian variation in copper and zinc in man. J Appl Physiol 31: 88-92, 1971.

25. Lau JY, Davis GL, Kniffen J, et al: Significance of serum hepatitis C virus RNA levels in chronic hepatitis C. Lancet 341: $1501-1504,1993$
26. Simmonds P, Alberti A, Alter HJ, et al: A proposed system for the nomenclature of hepatitis $C$ viral genotypes. Hepatology 19 : 1321-1324, 1994

27. Ichida F, Tsuji T, Omata M, et al: New Inuyama classification: new criteria for histological assessment of chronic hepatitis. Int Hepatol Commun 6: 112-119, 1996.

28. Brunt EM, Janney CG, Di Bisceglie AM, Neuschwander-Tetri BA and Bacon BR: Nonalcoholic steatohepatitis: a proposal for grading and staging the histological lesions. Am J Gastroenterol 94: 2467-2474, 1999.

29. Okuda M, Li K, Beard MR, Showalter LA, Scholle F, Lemon SM and Weinman SA: Mitochondrial injury, oxidative stress and antioxidant gene expression are induced by hepatitis $\mathrm{C}$ virus core protein. Gastroenterology 122: 366-375, 2002.

30. Hayashi H, Takikawa T, Nishimura N, Yano M, Isomura $T$ and Sakamoto N: Improvement of serum aminotransferase levels after phlebotomy in patients with chronic active hepatitis C. Am J Gastroenterol 89: 986-989, 1994.

31. Koike $\mathrm{K}$ and Miyoshi $\mathrm{H}$ : Oxidative stress and hepatitis $\mathrm{C}$ viral infection. Hepatol Res 34: 65-73, 2006.

32. Fujita N, Horiike S, Sugimoto R, et al: Hepatic oxidative DNA damage correlates with iron overload in chronic hepatitis C patients. Free Radic Biol Med 42: 352-362, 2007.

33. De Sanctis V, Gamberini MR, Borgatti L, Atti G, Vullo C and Bagni B: Alpha and beta cell evaluation in patients with thalassaemia intermedia and iron overload. Postgrad Med J 61: 963-967, 1985.

34. Dehshal MH, Hooghooghi AH, Kebrayaeezadeh A, et al: Zinc deficiency aggravates abnormal glucose metabolism in thalassemia major patients. Med Sci Monit 13: CR235-CR239, 2007.

35. Miura K, Taura K, Kodama Y, Schnabl B and Brenner DA Hepatitis $C$ virus-induced oxidative stress suppresses hepcidin expression through increased histone deacetylase activity. Hepatology 48: 1420-1429, 2008.

36. Mifuji R, Kobayashi Y, Ma N, et al: Role of transferrin receptor 2 in hepatic accumulation of iron in patients with chronic hepatitis C. J Gastroenterol Hepatol 21: 144-151, 2006.

37. Fernandez-Real JM, Lopez-Bermejo A and Ricart W: Cross-talk between iron metabolism and diabetes. Diabetes 51: 2348-2354, 2002. 